\title{
Nephrotic Syndrome and Acute Renal Failure Apparently Induced by Sunitinib
}

\author{
Ying-Shou Chen ${ }^{a, c}$ Chien-Liang Chen ${ }^{a, c}$ Jyh- \\ Seng Wang ${ }^{a, b}$ \\ aDivision of Nephrology, Department of Medicine, ${ }^{b}$ Department of Pathology, \\ Kaohsiung Veterans General Hospital, Kaohsiung, and 'Department of Medicine, \\ School of Medicine, National Yang-Ming University, Taipei, Taiwan
}

\section{Key Words}

Sunitinib $\cdot$ Nephrotic syndrome $\cdot$ Ischemic acute tubular necrosis

\begin{abstract}
We report a case of nephrotic syndrome and acute renal failure apparently induced by sunitinib. A 67-year-old man with a history of metastatic renal cell carcinoma presented with progressive kidney dysfunction with proteinuria, general edema, and body weight gain of $21 \mathrm{~kg}$ after undergoing 3 weeks of sunitinib therapy. The patient had taken no other over-the-counter medications, and all other possible causes of nephrotic syndrome were excluded. The Naranjo Adverse Drug Reaction Probability Scale score for this event was 6 , indicating a high probability that the observed presentations were associated with use of the drug. However, despite the discontinuation of sunitinib, his condition deteriorated, and hemodialysis was initiated for respiratory distress. A renal biopsy was performed, which revealed ischemic acute tubular necrosis with minimal change nephropathy. In conclusion, nephrologists and oncologists should be aware that nephrotic syndrome with ischemic acute tubular necrosis is a possible adverse effect of sunitinib. For early diagnosis of this condition and to avoid renal damage, we recommend differential diagnosis of serum creatinine and proteinuria in patients undergoing sunitinib therapy.
\end{abstract}

\section{Introduction}

Sunitinib is a small molecule that inhibits multiple tyrosine kinase receptors. In 2006, the United States Food and Drug Administration approved this drug for treating clear cell metastatic renal cell carcinoma [1]. In patients given sunitinib, median progression-free survival is significantly longer than in patients given the standard treatment with interferon- $\alpha$, and some patients exhibit tumor regression [2]. Its known adverse effects 
include fatigue, malaise, diarrhea, skin abnormalities, and cytopenia. This report is the first to describe a case of nephrotic syndrome and ischemic acute tubular necrosis apparently related to sunitinib therapy.

\section{Case Report}

We report the case of a 67 -year-old man who was treated with sunitinib for metastatic clear cell renal cell carcinoma. In August 2008, he was diagnosed with right huge renal tumor with inferior vena cava compression in the Chang Gung Memorial Hospital, Kaohsiung Branch, and then he visited our urology outpatient department for a tumor biopsy and management. After admission in October 2008, he refused the tumor biopsy, but agreed to tyrosine kinase inhibitor sunitinib for suspected metastatic renal cell carcinoma. Before beginning the sunitinib therapy, blood pressure was $116 / 61 \mathrm{~mm} \mathrm{Hg}$ with medical control for hypertension, serum creatinine was $1.1 \mathrm{mg} / \mathrm{dl}$, albumin level was $4.0 \mathrm{~g} / \mathrm{dl}$, and cholesterol was $57 \mathrm{mg} / \mathrm{dl}$, triglyceride was $114 \mathrm{mg} / \mathrm{dl}$ and the patient had no proteinuria. After starting the sunitinib therapy with $37.5 \mathrm{mg}$ daily at the end of November, he began to exhibit foamy urine and gradually decreasing urine excretion as well as a $21-\mathrm{kg}$ weight gain. His response to furosemide and water with salt restriction was poor, and general edema, dyspnea on exertion, and oliguria developed. After 3 weeks of therapy, sunitinib was discontinued on December 18, 2008. However, urine excretion and edema showed no improvement 2 weeks after discontinuing sunitinib (fig. 1). The patient was readmitted in January 2009 with serum creatinine $5.1 \mathrm{mg} / \mathrm{dl}$, albumin level $1.5 \mathrm{~g} / \mathrm{dl}$, and sugar level 107 $\mathrm{mg} / \mathrm{dl}$. Urinalysis revealed proteinuria with bland sediment. No non-steroid anti-inflammatory drugs, antibiotics, or herbal supplements were used throughout the course of the sunitinib therapy. Physical examination revealed high blood pressure $161 / 83 \mathrm{~mm} \mathrm{Hg}$, jugular venous pressure $10 \mathrm{~cm}$, bilateral basal fine crackle breathing sounds, severe lower leg and scrotal edema without skin rash and arthralgia. Spot urine protein/creatinine was 20.0 (g/g). Serum complement, anti-neutrophil antibody, cryoglobulin, protein electrophoresis, and rheumatoid factor were negative, and no hematological features of thrombotic microangiopathy were observed. Renal sonography revealed a large $(14.8 \times 13.3 \mathrm{~cm})$ tumor and normal left renal size without hydronephrosis. Response to high-dose furosemide and albumin supplement was poor, and temporal hemodialysis was done for 2 weeks due to respiratory distress. After a discussion with the patient and his family, a right tumor and left renal biopsy was performed on January 23, 2009. Clear cell renal cell carcinoma was confirmed. Immunofluorescence revealed negative IgG, IgA, IgM, C1q, C3, kappa and lambda light deposition, and glomeruli with no remarkable change other than mild mesangial expansion. Electron microscopy showed normal thickness of the glomerular basement membrane and segmental subendothelial widening, mild small dense deposits in the mesangial area, marked and extensive epithelial cell foot process effacement, moderate epithelial cell microvillous transformation (fig. 2a), attenuation of the brush border, and sloughing tubule cell (fig. 2b). After temporal hemodialysis, urine quantity improved. Serum creatinine also improved (creatinine $2.8 \mathrm{mg} / \mathrm{dl}[213.53 \mu \mathrm{mol} / \mathrm{l}]$ ). However, daily protein loss increased to $48.1 \mathrm{~g}$ despite having discontinued sunitinib for 10 weeks. The urine protein loss decreased to $9.85 \mathrm{~g} /$ day and serum creatinine to $1.8 \mathrm{mg} / \mathrm{dl}$ after the patient was given prednisolone $30 \mathrm{mg}$ daily for 4 weeks.

\section{Discussion}

The patient had taken no other over-the-counter medications, and all other possible causes of minimal change nephropathy were excluded. Before beginning the sunitinib therapy, he was proteinuria-free and had normal renal function. The Naranjo Adverse Drug Reaction Probability Scale score for this event was 6, indicating a probable association of the event with the drug. Sunitinib is an oral, small-molecule, multi-targeted receptor tyrosine kinase inhibitor of targets such as vascular endothelial growth factor (VEGF) and platelet-derived growth factor receptor. The drug is administered orally once daily in a 4-weeks-on/2-weeks-off cycle. The VEGF is important for maintaining normal glomerular endothelial function. In normal mice and rats, circulating VEGF-A can reportedly be neutralized by injection of anti-VEGF-A antibodies, or soluble VEGF-R1 induced proteinuria, glomerular endothelial cell detachment, and suppression of nephrin, an important protein for maintaining the glomerular slit diaphragm. Such findings implicate the role of VEGF in the maintenance of the glomerular filtration barrier that 
prevents leakage of plasma proteins into urine. Proteinuria is common in mice treated with soluble VEGF-R1 and in humans treated with anti-VEGF antibody [3, 4]. However, the patient described in this report developed persistent proteinuria and required dialysis even after discontinuing sunitinib. Although a few reports have described renal dysfunction induced by sunitinib, including acute interstitial nephritis [5] and thrombotic microangiopathy [6], this study is the first to report nephrotic syndrome with acute renal failure and ischemic acute tubular necrosis associated with this agent, and this is the first report of diagnosis by histological study. We suspect that sunitinib may induce nephrotic syndrome by an immune reaction combined with amplification of the underlying pathogenesis of minimal change nephropathy, which may present with a transient episode of circulatory insufficiency during diuretic treatment and induce ischemic acute tubular necrosis [7]. Oral anticancer agents such as sunitinib are generally considered safer than other anticancer agents and more tolerable by patients with poor condition or by patients with organ failure that is untreatable by standard cytotoxic chemotherapy. This case report suggests that oncologists and nephrologists should be vigilant for possible minimal change nephropathy and ischemic acute tubular necrosis related to sunitinib treatment, especially in patients with renal cell carcinoma.

Until now, no guidelines for monitoring serum creatinine in patients undergoing sunitinib therapy have been proposed. We recommend monitoring of serum creatinine and proteinuria immediately after initiating sunitinib therapy for early diagnosis of minimal change nephropathy and ischemic acute tubular necrosis and to avoid renal damage.

Fig. 1. Kidney function assessed by serum creatinine concentration and body weight after sunitinib treatment in a 67-year-old male with a history of metastatic renal cell carcinoma.

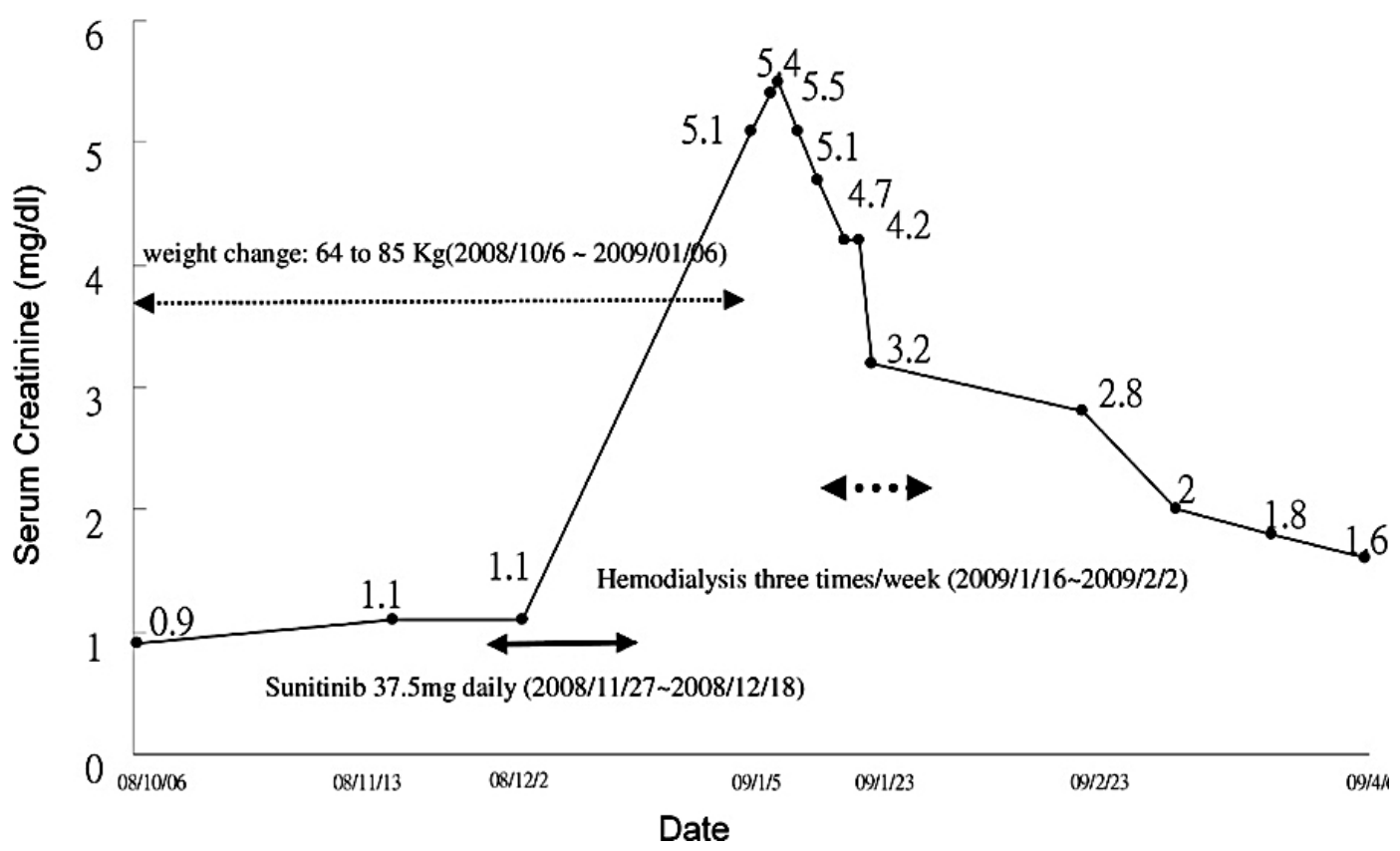


Fig. 2. a Marked epithelial cell foot process effacement and extensive and moderate epithelial cell microvillous transformation without subendothelial electronlucent fluffy material depositions (signs of coagulation). b Attenuation of the brush border and sloughing tubule cell consistent with ischemic acute tubular necrosis.

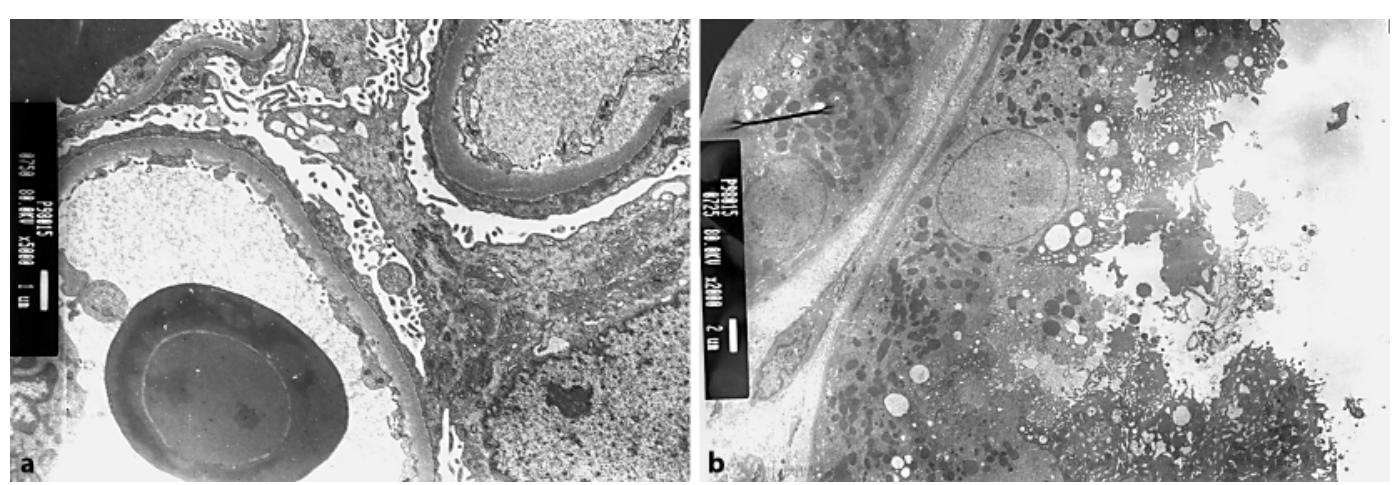




\section{References}

1 Izzedine $\mathrm{H}$, Billemont $\mathrm{B}$, Thibault $\mathrm{F}$, Rixe $\mathrm{O}$ : New challenges in kidney cancer therapy: sunitinib. Ann Oncol 2007;18:83-86.

2 Motzer RJ, Huston TE, Tomczak P, et al: Sunitinib versus interferon alfa in metastatic renal-cell carcinoma. N Engl J Med 2007;11:115-124.

-3 Maynard SE, Min JY, Merchan J, et al: Excess placental soluble fms-like tyrosine kinase 1 (sFlt1) may contribute to endothelial dysfunction, hypertension, and proteinuria in preeclampsia. J Clin Invest 2003;111:649-658.

-4 Sugimoto H, Hamano Y, Charytan D, et al: Neutralization of circulating vascular endothelial growth factor (VEGF) by anti-VEGF antibodies and soluble VEGF receptor 1 (sFlt-1) induces proteinuria. J Biol Chem 2003;278:12605-12608.

5 Winn SK, Ellis S, Savage P, Sampson S, Marsh JE: Biopsy-proven acute interstitial nephritis associated with the tyrosine kinase inhibitor sunitinib: a class effect? Nephrol Dial Transplant 2009;24:673-675.

6 Bollée G, Patey N, Cazajous G, et al: Thrombotic microangiopathy secondary to VEGF pathway inhibition by sunitinib. Nephrol Dial Transplant 2009;24:682685.

7 Chen CL, Fang HC, Chou KJ, et al: Increased endothelin 1 expression in adultonset minimal change nephropathy with acute renal failure. Am J Kidney Dis $2005 ; 45: 818-825$. 